STUDI

FRANCESI

\section{Studi Francesi}

Rivista quadrimestrale fondata da Franco Simone

170 (LVII | II) | 2013

Varia

\title{
Aa. Vv., Renée Vivien, une femme de lettres entre deux siècles (1877-1909)
}

\section{Maria Emanuela Raffi}

\section{(2) OpenEdition}

12 Journals

\section{Edizione digitale}

URL: https://journals.openedition.org/studifrancesi/3185

DOI: $10.4000 /$ studifrancesi.3185

ISSN: 2421-5856

\section{Editore}

Rosenberg \& Sellier

\section{Edizione cartacea}

Data di pubblicazione: 1 juillet 2013

Paginazione: 482

ISSN: 0039-2944

\section{Notizia bibliografica digitale}

Maria Emanuela Raffi, «Aa. Vv., Renée Vivien, une femme de lettres entre deux siècles (1877-1909)», Studi Francesi [Online], 170 (LVII | II) | 2013, online dal 30 novembre 2015, consultato il 02 février 2023. URL: http://journals.openedition.org/studifrancesi/3185 ; DOI: https://doi.org/10.4000/studifrancesi.3185

Questo documento è stato generato automaticamente il 2 février 2023.

\section{(c) (i) (3)}

Creative Commons - Attribuzione - Non commerciale - Non opere derivate 4.0 Internazionale - CC BYNC-ND 4.0

https://creativecommons.org/licenses/by-nc-nd/4.0/ 


\title{
Aa. Vv., Renée Vivien, une femme de lettres entre deux siècles (1877-1909)
}

\author{
Maria Emanuela Raffi
}

\section{NOTIZIA}

AA. VV., Renée Vivien, une femme de lettres entre deux siècles (1877-1909), textes réunis par NICOLE G. ALBERT ET BRIGITTE ROLLET, Paris, Champion, 2012, pp. 216.

Questa raccolta di saggi, interamente dedicata alla scrittrice anglo-francese Pauline Mary Tarn, in letteratura Renée Vivien, frutto di un convegno tenuto all'Université de Londres a Parigi nel centenario della sua morte, fa luce sull'opera di un'autrice poco nota, studiosa e continuatrice dell'opera saffica, che ha tradotto dal greco nel 1903. I dieci saggi che, assieme alla «Préface» di Nicole G. Albert, costituiscono il volume illustrano i diversi aspetti dell'opera poetica dell'autrice - dodici raccolte pubblicate fra il 1901 e il 1908, più altre due apparse postume, analizzano il suo unico romanzo Une femme m'apparut del 1905, presentano rapporti e relazioni con altri autori (Lucie Delarue-Mardrus e soprattutto Jean-Charles Brun), nonché la «postérité» di Renée Vivien in Francia e in Spagna, con Maria-Mercé Marçal.

2 Il volume è arricchito da una serie di lettere della scrittrice alla sorella Toinette, da un certo numero di lettere inedite a Charles-Brun e alla moglie, da scritti critici su Renée Vivien e da illustrazioni e ritratti della scrittrice. 